\author{
Girish B. Nair \\ Michael S. Niederman
}

\section{Ventilator-associated pneumonia prevention: response to Silvestri et al.}

Accepted: 14 March 2015

Published online: 31 March 2015

(C) Springer-Verlag Berlin Heidelberg and ESICM 2015

Dear Editor,

We have read the comments of Silvestri et al. [1] and appreciate their interest in our article [2]. We agree that the data supporting SDD are strong, as described in a recent metaanalysis [3]. However, as they acknowledged, space limitations prevented us from discussing all topics, including SDD. In our review, we did allude to the principles of SDD when we commented that microaspiration of oropharyngeal contents, contaminated by endogenous flora, is a target of several prevention interventions. However, we did not, as Silvestri et al. suggest, omit further discussion of SDD because of there being no uncertainty about its value. In fact, there is an ongoing debate and uncertainty about possible benefits and harms related to SDD and its implementation $[4,5]$. When discussing prevention in our review, we did comment on the controversy about "zero VAP". In many ICUs, the use of ventilator bundles, which often include oral care (sometimes with chlorhexidine gluconate), has dramatically reduced (but not eliminated) the frequency of VAP. In this setting, the incremental utility of SDD remains uncertain. Many of the studies of SDD were done in an era when VAP rates were high, and ventilator bundles and routine oral care were not utilized. We believe that the mortality benefit of SDD in ICUs that routinely use ventilator bundles, have low rates of VAP, but high rates of MDR pathogens, still needs to be demonstrated, to justify using the widespread use of this strategy.

Conflicts of interest The authors have no conflict of interest related to the topic of this letter.

\section{References}

1. Silvestri L, de la Cal MA, van Saene HKF (2015) Ventilator-associated pneumonia prevention: the issue is the control of oropharyngeal and gut overgrowth. Intensive Care Med. doi: 10.1007/s00134-014-3750-0
2. Nair GB, Niederman MS (2015) Ventilator-associated pneumonia: present understanding and ongoing debates. Intensive Care Med 41:34-48. doi:10.1007/s00134-014-3564-5

3. Roquilly A, Marret E, Abraham E, Asehnoune K (2015) Pneumonia prevention to decrease mortality in intensive care unit: a systematic review and meta-analysis. Clin Infect Dis 60:64-75

4. Francis JJ, Duncan EM, Prior ME, Maclennan GS, Dombrowski S, Bellingan GU, Campbell MK, Eccles MP, Rose L, Rowan KM, Shulman R, Peter R, Wilson A, Cuthbertson B (2014) Selective decontamination of the digestive tract in critically ill patients treated in intensive care units: a mixedmethods feasibility study (the SuDDICU study). Health Technol Assess 18(25):1-170

5. Halaby T, Al Naiemi N, Kluytmans J, van der Palen J, Vandenbroucke-Grauls CM (2013) Emergence of colistin resistance in Enterobacteriaceae after the introduction of selective digestive tract decontamination in an intensive care unit. Antimicrob Agents Chemother 57(7):3224-3229

G. B. Nair · M. S. Niederman ( Winthrop-University Hospital, Mineola, NY 11501, USA

e-mail: msn9004@med.cornell.edu 